\title{
Decision Factors in Medical Tourism: Evidence from Burmese Visitors to a Hospital in Bangkok
}

\author{
Nay Lynn Yin Maung, *John Walsh \\ Shinawatra University, Bangkok, Thailand \\ *jcwalsh@siu.ac.th
}

\begin{abstract}
Medical tourism is a significant factor in Thailand's economy as the country aims to develop more high value-added activities to escape from the middle income trap. The country has a number of highly advanced private sector hospitals, with western-trained physicians and the legendary service levels provided in Thailand. There are several prime targets for promoting medical tourism, which include the Middle East and South Asia, as well as some western countries, but one which is often ignored is neighboring Myanmar. This country is emerging from military dictatorship and has an unequal society in which there are a number of wealthy individuals unable to find the level of medical service they require in their homeland. Many Burmese people speak English, which is the international language of tourism and medicine. For such people, Thailand is a logical destination in the search for high-quality medical tourism. However, little if any research has been conducted to determine the levels of satisfaction that patients and their carers have received in Thailand and what improvements in service would be required. This paper aims to fill that gap to some extent by reporting on a quantitative survey of 200 Burmese users of a well-known private sector hospital in Bangkok. Their levels of satisfaction are charted and this leads to discussion of the meaning of their visit and its overall impact and benefit.
\end{abstract}

Keywords: Hospital management, medical tourism, Myanmar, Thailand

\section{Introduction}

Tourism is a service industry which can generate income comparable to or more than other industries, especially for emerging economies. However, tourism can also be, if not properly controlled and maintained, a threat to the environment and also to the culture of a nation. Tourism is a human-oriented industry where the customer is at the centre of the tourism universe. The needs and wants of a customer play a very important role in promoting and gaining benefits from the tourism industry. Tourism destinations compete for customers on a global level and so will need high quality infrastructure to meet the needs of international visitors. Thailand has to a large extent already achieved this level of tourism development. According to Diithelm Travel (2006), the country's travel and tourism industry has contributed $6.7 \%$ (567 billion baht) to the GDP, as stated by the Tourism Satellite Accounting study by the World Travel and Tourism Council (WTTC). In the ten years since 1998, the number of international tourists coming to Thailand doubled and even though the average length of stay and average daily spending remained the same, overall revenue also more than doubled. Data for Myanmar residents visiting Thailand have only been available since 2001. The number of Myanmar tourists coming to Thailand has been very small compared to those from other countries; it rose from a mere 43,115 in 2001 to 75,183 in 2007, nearly doubling in size over that period, while a similar trend can be noted with Indian tourists. Average daily expenditure per person of Asian tourists was comparable to that of tourists from the more developed world and the amount of expenditure of the Burmese tourists is comparable to that of tourists from the United Kingdom. In this paper, Myanmar and Burma are used interchangeably. The main reason why medical tourism is becoming more popular in Asia, especially in the hubs of Singapore, Thailand and India, is the competitively lower prices with comparable standards to services from developed countries in the west. However, that reason does not always hold true for regional neighbors, where suitable services are not available in the home country and so a combined medical-pleasure tourism package across the border appears desirable. According to the Tourism Authority of Thailand (2003), in 2002, the number of foreign patients seeking treatment in Thailand grew by $13 \%$ over the previous year with some 632,300 foreigners visiting 33 private hospitals.

The Research Site: The research site is a hospital accredited by the Joint Commission International (JCI), the international arm of the organization that reviews and accredits American hospitals. It has also been 
accredited by the Institute of Hospital Quality Improvement \& Accreditation which is Thailand's own accreditation program, in 1999 and subsequently reaccredited. Established in 1980, and listed on the stock exchange of Thailand in 1989 with a market cap of over US\$1 billion, the hospital is the largest private hospital in Southeast Asia treating annually over one million patients, with over 400,000 foreign patients each year from some 190 countries. It provides a full range of tertiary medical services and there are more than 945 physicians on staff. This includes over 90,000 patients from the Middle East with 40,000 from the United Arab Emirates (Diethelm Travel, 2006). The hospital has 33 medical centres serving as one-stop centres for medical services and it has won the Tourism Authority of Thailand Award of Excellence in the category of Health Tourism. Patients from all over the world come to the hospital seeking medical care. Middle Eastern patients visiting it have soared from 5,000 in the year 2000 to nearly 70,000 last year, and could approach 100,000 this year, most of them coming from the United Arab Emirates, Oman and Qatar (Diethelm Travel, 2006). Majority shareholders are Thai, including the original family owners, although international interests are also strongly represented. One reason for the hospital's popularity is the availability of Western trained physicians and the transformation of the hospital environment to a hotel environment and the advanced technological facilities. In order to serve the multinational patients' requirements, the hospital has foreign language interpreters, on-site housing for visiting patients and their families, airport transfers, visa extension assistance and insurance processing to ensure a smooth and pleasant hospital stay for the patients as if they are staying in their local hospital. The hospital has authorized overseas representatives in 21 countries.

Research Problem: Medical tourism is becoming more and more popular in Southeast Asia. It is a business comparable to regular tourism and has a chance to overtake it in terms of revenues involved. This is becoming a trend not only in Asia but also for the rest of the world because of the existence of price gradients along which the flow of patients follows from places with higher price to lower price. Consequently, a question arises as to what makes the hospitals in Asia stand out as medical tourism destinations, in other words, what is and what would be the sustainable competitive advantage of medical centres in Asia. The answer seems to be price. The cost of different medical treatments, as well as surgical operations extending from cosmetic surgery, like a laser tattoo removal to surgical treatment for cancer and other malignant diseases are significantly lower, sometimes as low as one tenth, compared to that of the hospitals in more developed western countries, where people may be required to have pricy health insurance packages in order to survive the expensive costs of healthcare. However, the reasons behind people seeking medical care can be different, varying from country to country, as well as many other diverse factors, including socio-demographic factors, which influence the decision processes of individuals in choosing different hospitals. For example, people from developed countries usually come to a hospital in a developing country to receive a certain surgical treatment because of the lower cost, on the condition that the Asian hospital they chose must be able to provide services and standards comparable to that of those in the west. This is usually a prerequisite of their own health insurance policy. The situation is different if we consider a person coming to a developing country from a developing or underdeveloped country in search of reliable and up-to-date modern technologies and facilities and as well as treatment choices not available in the home country. For such a person, even the expenses for coming to such a hospital from his home country will be a serious factor to consider, not mentioning the skyrocketing medical bills that must be settled after treatment. Such a patient chooses a facility on the basis that expensive up-to-date technology and treatment options are not available in the home country where healthcare might be substandard and out of date. These two situations are opposites of each other.

It can easily be imagined that while it is easier for a person from a developed world to come to a developing country to seek medical treatment, the less privileged counterpart from a developing country will have limited choices as to the most economical and cost effective hospital, which might require life's savings to be consumed in order to receive the required treatment. However, people always believe that health is more important than wealth and will do whatever it takes to get treatment for themselves or their loved ones. Consequently, it is the duty of at least some healthcare providers, including hospitals, to care for everyone to enjoy according to globally accepted levels and standards at prices convenient people with smaller budgets. At this point, another question arises as to what these hospitals can and will do to meet the varying needs of their customers who come from different demographic and ethnic categories as well as of varying economic and geographic distributions. The answer to this question is that there should be a change in the practice of healthcare providers towards the value-based competition based on results so as to go beyond the customer expectation in order to forge a long-lasting and interdependent relationship between the healthcare providers and the healthcare seekers, which will 
benefit both. In order to forge such a fruitful relationship, healthcare providers should try to discover ways and means to understand consumer behavior and characteristics in order to provide custom-made services to meet and exceed customer expectations. This research was intended to answer those questions for the research site hospital. The aims of this research are: to find out more details about patients from Myanmar who are seeking medical attention in the hospital as to the demographics of this population, as well as their attitudes towards the hospital and the factors influencing their choices. This information should help the hospital to manage its resources effectively in order to serve patients from Myanmar while, at the same time, finding ways to promote their reputation to a wider population.

\section{Literature Review}

Medical Tourism: Medical tourism is also known as health tourism, health care tourism, therapeutic vacation as well as many other names which basically refer to the definitions presented below. Healthcare tourism was defined twenty years ago by Goodrich \& Goodrich as "the attempt on the part of a tourist facility (for example a hotel) or destination (in Baden, Switzerland) to attract tourists by deliberately promoting its health-care services and facilities, in addition to its regular tourist amenities" (as cited in Danell \& Mugomba, 2006:2).India, Indonesia, Malaysia, the Philippines, Singapore, Thailand and many other countries market themselves as major destinations for "medical tourism"(Turner, 2007).Turner (2007:303)also noted the following: "'Medical tourists" include patients trying to avoid treatment delays and obtain timely access to health care. Medical travelers also include uninsured Americans and other individuals unable to afford health care in their home settings. Destination nations regard medical tourism as a resource for economic development." Connell defines medical tourism as a popular mass culture "where people travel often-long distances to overseas destinations (India, Thailand, and Malaysia) to obtain medical, dental and surgical care while simultaneously being holidaymakers, in a more conventional sense..." (As cited in Danell \& Mugomba, 2006:3).

Tourism Research and Marketing (2006) described medical tourism as any form of travel from one's normal place of residence to a destination at which medical or surgical treatments is provided or performed. The travel undertaken must involve more than one night away from the country of residence. According to the Canadian Broadcasting Corporation (2004), countries that actively promote medical tourism include Cuba, Costa Rica, Hungary, India, Israel, Jordan, Lithuania, Malaysia and Thailand. Belgium, Poland and Singapore are now entering the field. Tourism Research and Marketing (2006), also noted that the global medical tourism market comprised over 19 million trips in 2005, with a total value of $\$ 20$ billion -experiencing double-digit growth annually, which is forecast to grow to 40 million trips, or $4 \%$ of global tourism volume, by 2010. This information shows that the growth of the medical tourism industry is very attractive and thus a great deal of competition will be witnessed during this decade. Although the sector represents just $4 \%$ of the total tourism industry, the stakes involved are very high at about $\$ 40$ billion. Other niche activities to be considered include wellness and spa tourism according to United Nations World Tourism Organization (2006:10), which also stated that "Singapore and India are vying for this niche market segment with a future focus on cosmetic surgery. Thailand, Malaysia, Sri Lanka and the Philippines have also targeted the wellness tourists with their spa attractions and Ayurvedic herbal treatments."

Medical Tourism in Thailand: According to the Tourism Authority of Thailand (2003), in 2002, the number of foreign patients seeking treatment in Thailand grew by $13 \%$ over the previous year with some 632,300 foreigners visiting 33 private hospitals. Of this total, expatriate residents in Thailand $(189,000)$, staff of international organizations and their family members and other visitors from the neighboring countries and Asia $(378,000)$, and 'visiting patients' from Europe $(63,000)$, represented $60 \%$ of the total. Tourists in need of medical attention or treatment during their stay in the country accounted for another $30 \%$, and individuals who specifically travelled to Thailand for medical treatment or health services accounted for another 10\%. From the information provided by Thailand Board of Investment (2007:1), "In 2005, the number of foreign patients arriving in Thailand, so-called medical tourists, topped one million and reached 1.4 million in 2006. The country has set a target of 2 million medical tourists by the year 2010."Pachanee and Wibulpolprasert (2006) observed that after the 1997 economic crisis, private health care providers, with the support of the government, embarked on new marketing strategies targeted at attracting foreign patients. Consequently, increasing numbers of foreign patients are visiting Thailand to seek medical care. According to Diethelm Travel (2006), Thai hospitals only began promoting 
their services heavily after the financial crisis. The research site alone attracted more than 400,000 foreigners last year - 55,000 from the US - which represented nearly half the hospital's total patients.

Figures released by the Association of Thai Private Hospitals indicated that a total of 970,000 foreign patients sought medical diagnosis and treatment in private hospitals in Thailand during 2003, generating a total income of about Baht 19,000 million (as cited in Bangkok Bank, 2007).According to Bangkok Bank (2007), Thailand's competitors in the medical care sector in Asia are as follows:

- Singapore, which has formed the Health Care Working Group in an effort to turn the country into the "Medical Hub of Asia".

- Malaysia, where the government and the private sector are cooperating to make the country Asia's "Health Tourism Hub".

- India, which reports an average rate of growth of 30 per cent annually in foreign patients seeking medical care.

- Hong Kong, which has opened the Cancer Center in an effort to make it Asia's "Medical Hub."

Diethelm Travel (2006) also reported that Thailand has also been a beneficiary of a wave of Middle Eastern patients seeking affordable high-quality care. Numbers from the region have risen dramatically

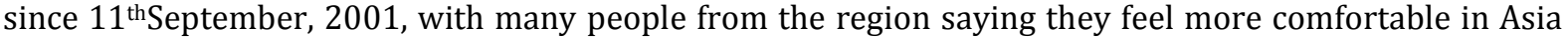
as the US tightens visa restrictions. The United States healthcare industry estimates it is losing about US $\$ 500$ million a year because of this (ibid.). Two thirds of the Thai economy depends on export of goods and services. Tourism, including health tourism, accounted for almost $8 \%$ of the gross domestic product (Wibulpolprasert, 2002). With the high potential and competitive advantages of the Thai health care systems, export of health services is strongly promoted to gain more foreign currency and boost economic growth (Pachanee \& Wibulpolprasert, 2006).The Thailand Board of Investment (2007:3) explained the potential of Thailand as a centre for medical tourism as follows: "For example, elective surgery in Thailand's best private hospitals is often one tenth the cost of the same procedure if performed in the United States. With the value of Organization for Economic Cooperation and Development [OECD] nations' health care sector having been estimated to be as high as US\$3 trillion and the United States at US $\$ 2$ trillion, the potential for Thailand is significant." Consequently, according to the Thailand Board of Investment (2007), the Thai government adopted a five-year strategic plan to develop the country's capacity into a "Centre for Excellent Health in Asia."Beyond medical tourism, Thailand is also extending its ability not just in medical tourism but also in other related areas as, "...Thailand excels in the medical care it delivers on a daily basis to patients from over 190 countries, the Kingdom is also gaining recognition as a location for research and for clinical trials (Thailand Board of Investment, 2007:3)."

The Dark Side of Medical Tourism: Turner (2007:303) argued that, "However, attracting patients to countries such as India and Thailand could increase regional economic inequalities and undermine health equity. International medical travel might also have unintended, undesired outcomes for patients seeking affordable health care." Further, reductions in health benefits offered by states and employers will likely increase the number of individuals looking for affordable medical care in a global market of privatized, commercial health care delivery (Turner, 2007). Pachanee \& Wibulpolprasert (2006:1\&16)also explained that, "The increasing demand and much higher financial incentives from the urban private providers have attracted health personnel, particularly medical doctors, from the rural public health facilities" and that "Since 2001, because of improving economy and the influx of foreign patients, human resources distribution becomes worsened." Promoting health tourism should be attempted, therefore, with the awareness that there are negative aspects to the activity and the issues of equity and access to good quality health care for all citizens should be considered. There is a further question concerning why this influx of medical tourists from around the developed world should choose between Thailand and its competitors. The answer is cost difference. From the perspective of the developed world, it would be beneficial to stop this outflow of medical tourists by finding out where the leak is and plugging it by mending their health service systems. A developing country like Myanmar needs to stop the outflow of medical tourists seeking better and more modern treatment facilities and techniques because of the ever increasing magnitude of foreign currency and lost opportunities for training experience for its medical personnel. The country should figure out how to put a stop to that outflow by studying what was causing such drainage from the health system and also the need to reform the health system can never be taken lightly. What went wrong and how to correct it can only be learnt from the mistakes of other nations and states should remodel and reform their strategies to take into account their own politics, economics and culture. 
Characteristics, Attitudes, Satisfaction and Decision Factors: This research aims to determine the characteristics, attitudes and decision factors involved in choosing the research site by the residents of Myanmar, according to a standard model of consumer behavior. Even though they belong to a special subgroup and might have certain particular characteristics, the same principles should be able to be applied to medical tourists, since they are still foreign tourists in another land. Who they are, what their attitudes are, how they can be satisfied and how they make decisions, both pre-purchase and postpurchase, would not be entirely different from a normal tourist. Belch and Belch (2007) define consumer behavior as "the process and activities people engage in when searching for, selecting, purchasing, using, evaluating, and disposing of products and services so as to satisfy their needs and desires."The wellknown definition of consumer behavior by Belch and Belch (2007) is "... the process and activities people engage in when searching for, selecting, purchasing, using, evaluating, and disposing of products and services so as to satisfy their needs and desires" (as cited in Abdallat \& El-Emam, (n.d)).Research by Wesley, Lehew \& Woodside (2006) found that the thoughts, decisions and behavior patterns for one activity bear upon the thoughts, decisions and behavior patterns for a host of activities. Each tourist destination offers a variety of services and each tourist has the opportunity to choose - under the influence of different variables (e.g. age, income, cost, risk, distance etc) - from a series of available alternatives (Kozak, 2002, as cited in Armario, 2008:370). A stream of research has tried to classify the main attributes of any particular destination (Kale \& Weir, 1986; Laws, 1995; Sirakaya, McLelllan \& Uysal, 1996, as cited in Armario, 2008:370). Such items include climate, culture, architecture, transport, entertainment and cost (Kozak, 2002, as cited in Armario, 2008:370), whereas attributes such as the destination's image help to strengthen these factors (Rodríguez et al., 2006, as cited in Armario, 2008:370).

Marketing and environmental stimuli enter the buyer's consciousness. The buyer's characteristics and decision process lead to certain purchase decisions. A consumer's buying behavior is influenced by cultural, social, personal and psychological factors. Culture, subculture and social class can be particularly important in buying behavior. In addition to cultural factors, a consumer's behavior is influenced by such social factors as reference groups, family and social roles and statuses. A buyer's decisions are also influenced by personal characteristics. These include the buyer's age and stage in the life cycle, occupation, economic circumstances, lifestyle, and personality and self-concept. A person's buying choices are influenced by four major psychological factors: motivation, perception, learning, beliefs and attitudes. Research into all these factors can provide clues as to how to reach and serve consumers more effectively (Kanhasiri, 2005). Research by Armario (2008) suggested that the motivations that lead an individual are classified in the literature as Push-and-Pull factors (Dann, 1977; Uysal\& Hagan, 1993; Yoon \&Uysal, 2005, as cited in Armario, 2008:370). 'Push' factors refer to intangible aspects, i.e. the individual's intrinsic desires (Crompton, 1979, as cited in Armario, 2008:370) linked to internal and emotional factors. Such motivations include the desire for rest, adventure, relaxation, health, social and family relationships (Yoon \&Uysal, 2005, as cited in Armario, 2008:371). Led by these factors, tourists travel to escape from their routine and to live new experiences. 'Pull' factors relate to the tangible characteristics of the trip, as well as the image or degree of attractiveness that the chosen destination holds (Rodríguez et al., 2004, as cited in Armario, 2008: 371).

Being a form of tourists themselves, the medical tourists also must follow a decision making process to choose which hospital to choose as evidenced in "Choosing a holiday destination is a rational decision process involving different factors" (McGehee, Loker-Murphy \& Uysal, 1996: 367): the tourist feels the need to travel and looks for a "product" which initially may offer the greatest satisfaction to fulfill that need (Armario, 2008). In such a process, the tourist feels 'pushed' by internal and emotional factors, as well as attracted by the characteristics of the destination and the availability of activities (Crompton, 1979; Dann, 1977; Uysal \& Jurowski, 1994). An especially interesting aspect of this argument is whether external sources of motivation have a greater effect than internal sources of motivation on the level of tourist satisfaction (Yoon \& Uysal, 2005). There are certain risks associated with service purchases at various stages. During the purchase stage, there is a higher level of risk perceived by consumers. As an example, Hoffman \& Bateson (2006) explained that a customer may have never undergone surgery before. Moreover, even though the surgeon has performed the operation successfully in the past, the patient is not guaranteed that this particular surgery will end with the same successful outcome. There are five risks associated with customer perception. They are financial risk, performance risk, physical risk, social risk and psychological risk (ibid.). There is a pre-purchase stage consideration which is the 
importance of personal sources of information. Hoffman and Bateson (2006) pointed out that research has shown that in the area of communications, personal forms such as word-of-mouth references and information from opinion leaders are often given more importance than company-controlled communications. Other pre-purchase stage considerations include the fact that consumers of services tend to evaluate a smaller number of alternative sources of supply during this stage for a variety of reasons and the third consideration is that "... self-service as a viable alternative whereby the selfprovision often becomes a viable alternative" (Hoffman \& Bateson, 2006: 97).

\section{Methodology}

Research Design: This was a quantitative research study designed to discover and analyze the relationship between the demographic and other relevant characteristics, the decision factors that the respondents believed were important in choosing a hospital overseas, the attitudes of the patients, how satisfied they were with different aspects of the services provided by the hospital. It was a cross sectional survey carried out within 30 days which obtained a convenience sample of 200 new and first-time patients coming to the hospital for various reasons. It was judged that this would be a sufficient number of responses given the nature and quantity of Burmese visitors attending the hospital. This primary data was amalgamated into the secondary data obtained from a variety of relevant sources. The questionnaire employed was created after consultation with experts in the field and in the light of existing instruments. Both English and Burmese versions were created and a short pre-test was used to determine its suitability for use. Questionnaires were checked and then entered into a database for subsequent statistical analysis. Extensive use was made of Likert scale questions, with average scores calculated from the results observed. There are some limitations to the research which should be acknowledged: these are related to the extent of time and space occupied by the survey period. These are necessarily constrained but all reasonable precautions have been taken to make the survey as representative of the overall population as might be reasonably expected.

\section{Findings}

Analysis of the Characteristics of the Patients: Among the respondents, $8 \%$ were aged $20-29,26.5 \%$ $30-39,27 \% 40-49,17.5 \% 50-59,5 \% 70-79$ and $0.5 \%$ other ages. Most (121) respondents were male $(60.5 \%)$ and 79 were female (39.5\%). The highest level of education achieved was reported to be graduate degree $(6 \%)$, undergraduate degree $(70 \%)$ and high school diploma $(24 \%)$. Some $36.5 \%$ of the sample is single, $62 \%$ married and the remaining $1.5 \%$ chose the 'other' option. In terms of income, respondents were presented with a range of options for ease of calculation and to minimize the need to reveal sensitive information. It was found that $10.5 \%$ of respondents earned less than 500,000 kyats per month, with $20.5 \%$ in the $500,000-1,000,000$ range, $17.5 \%$ in the $1-2,000,000$ kyats per month range and $51.5 \%$ more than this amount. At the time of the research, the official exchange rate was US $\$ 1=6.51$ kyats, while the unofficial street rate was US $\$ 1=1,200$ kyats. Sometimes the respondent was a patient and sometimes another person speaking on behalf of the patient, if the latter was unable or unwilling to answer. The majority of the respondents were outpatients (92.5\%), with the remainder inpatients (7.5\%). Initially, it had been planned that half the respondents would be outpatients and half inpatients but many of the people in the latter category were unwilling to be involved in the survey and preferred privacy. Consequently, the researcher and the hospital staff decided to concentrate mostly on the outpatient clinics.

In terms of treatment categories, those seeking treatment for heart-related conditions were $11 \%$ of the total, for bone-related problems (2\%), digestive disorders (18\%), brain/neurology problems (3\%), checkup (29\%), dermatology /cosmetic purposes (5\%), eye problems (4\%), dentistry (2\%) and other reasons $(26 \%)$. The total number of responses for this question was 238 , which is higher than the sample size because some patients were attending the hospital for more than one reason. Respondents were asked whether they had visited any other hospitals before the one where they were interviewed. This was to try to assess how consumer behavior took place and which criteria people considered to be important. It was found that $19 \%$ of respondents had visited other hospitals before but $81 \%$ had not. Respondents were then asked about information sources concerning the hospital. Respondents could choose more than one answer: 99 respondents said their friends were a source of information, 34 nominated their physicians, 109 their relatives, 33 mentioned the internet and there were 54 responses concerning other sources. 
Satisfaction with Hospital Services: Likert scale questions were employed to determine satisfaction levels with various aspects of the hospital service, as displayed in the table below.

Table 1: Satisfaction Levels with Hospital Services; source: Original Research

\begin{tabular}{|c|c|c|c|c|c|c|c|}
\hline Factor & Mean & S.D. & $\begin{array}{l}\text { Satisfaction } \\
\text { Level }\end{array}$ & Factor & Mean & S.D. & $\begin{array}{l}\text { Satisfaction } \\
\text { Level }\end{array}$ \\
\hline $\begin{array}{l}\text { Doctor quality } \\
\text { and experience }\end{array}$ & 1.04 & 0.196 & Very satisfied & Technology & 1.03 & 0.157 & $\begin{array}{l}\text { Very } \\
\text { satisfied }\end{array}$ \\
\hline $\begin{array}{l}\text { Treatment } \\
\text { facilities }\end{array}$ & 1.03 & 0.157 & Very satisfied & Facilities & 1.15 & 0.353 & $\begin{array}{l}\text { Very } \\
\text { satisfied }\end{array}$ \\
\hline Reputation & 1.11 & 0.386 & Very satisfied & Administration & 1.71 & 1.073 & $\begin{array}{l}\text { Very } \\
\text { satisfied }\end{array}$ \\
\hline Location & 1.25 & 0.597 & Very satisfied & Trustworthiness & 1.26 & 0.540 & $\begin{array}{l}\text { Very } \\
\text { satisfied }\end{array}$ \\
\hline Service & 1.26 & 0.542 & Very satisfied & Recommendation & 1.69 & 0.779 & $\begin{array}{l}\text { Very } \\
\text { satisfied }\end{array}$ \\
\hline Value for money & 2.17 & 1.299 & Satisfied & Communications & 2.61 & 1.259 & Neutral \\
\hline
\end{tabular}

While it is evident that respondents were happy with the services provided at the hospital, subsequent questions did determine that they would prefer to access services at home if equivalent levels of quality were available there. Additionally, $65 \%$ of respondents replied that they would return to the hospital in addition to any revisits required by the doctor on this visit, while $96 \%$ of respondents agreed that they would be prepared to recommend the hospital to other people. Satisfaction levels were generally in line with the importance attached to them by respondents with one exception, which was communications. This was rated the second most important factor in terms of choosing a hospital but was the least satisfactory in terms of performance. It is possible that language barriers may have contributed to this situation.

Summary of Hypothesis Testing: The hypotheses in the table below were tested using suitable statistical techniques and in null format.

Table: Summary of Hypothesis Testing; source: Original Research

\begin{tabular}{lll}
\hline No & Hypothesis & Status \\
\hline H1 & $\begin{array}{l}\text { There is a significant relationship between demographic characteristics (age, } \\
\text { gender, occupation, marital status, education level and monthly income) and the } \\
\text { decision to choose the hospital (only available here, not the only reason, enjoy } \\
\text { quality service and other reasons). }\end{array}$ & \\
& &
\end{tabular}

H2 There is a significant relationship between other characteristics (source of information, visited other hospitals, financial support, patient category and treatment category) and the decision to choose the hospital (only available here, not the only reason, enjoy quality service and other reasons).

H3 There is a significant relationship between the attitudes toward the private hospitals in home country (expenses, facility, technology, quality of care, doctor's ability and management efficiency) and the decision to choose the hospital (only available here, not the only reason, enjoy quality service and other reasons).

H4 There is a significant relationship between the factors influencing the decision making process and the decision to choose the hospital (only available here, not the only reason, enjoy quality service and other reasons).

H5 There is a significant relationship between demographic characteristics (age, gender, education level, marital status, occupation and monthly income) and the decision factors in choosing a hospital overseas (doctors' qualification, wide treatment variety, reputation, location, service, value for money, technology, facility, administration, trust, recommendation and communication).

H6 There is a significant relationship between other characteristics (visited other hospitals, source of information, patient category, treatment category and the need for financial support) and the decision factors in choosing a hospital

Not supported

Supported

Not supported

Not supported 
overseas (doctors' qualification, wide treatment variety, reputation, location, service, value for money, technology, facility, administration, trust, recommendation and communication).

H7 There is a significant relationship between attitudes toward private hospitals in home country (expenses, facility, technology, quality of care, doctor's ability and management efficiency) and the decision factors in choosing a hospital overseas (doctors' qualification, wide treatment variety, reputation, location, service, value for money, technology, facility, administration, trust, recommendation and communication).

H8 There is a significant relationship between demographic characteristics (age, gender, occupation, marital status, education level and monthly income) and the satisfaction after experiencing hospital services provided by the hospital (doctors' qualification, wide treatment variety, reputation, location, service, value for money, technology, facility, administration, trust, recommendation and communication).

H9 There is a significant relationship between other characteristics (source of information, visited other hospitals, financial support, patient category and treatment category) and the satisfaction after experiencing hospital services provided by the hospital (doctors' qualification, wide treatment variety, reputation, location, service, value for money, technology, facility, administration, trust, recommendation and communication).

H10 There is a significant relationship between the attitudes toward the private hospitals in the home country (expenses, facility, technology, quality of care, doctor's ability and management efficiency) and the satisfaction after experiencing hospital services provided by the hospital (doctors' qualification, wide treatment variety, reputation, location, service, value for money, technology, facility, administration, trust, recommendation and communication).

H11 There is a significant relationship between demographic characteristics (age, gender, occupation, marital status, education level and monthly income) and the attitudes formed after experiencing hospital services provided by the hospital (still come if equivalent service available at home, likeliness to come back, recommend someone).

H12 There is a significant relationship between other characteristics (source of information, visited other hospitals, financial support, patient category and treatment category) and the attitudes formed after experiencing hospital services provided by the hospital (still come if equivalent service available at home, likeliness to come back, recommend someone).

H13 There is a significant relationship between the attitudes toward the private hospitals in the home country (expenses, facility, technology, quality of care, doctor's ability and management efficiency) and the attitudes formed after experiencing hospital services provided by the hospital (still come if equivalent service available at home, likeliness to come back, recommend someone).

H14 There is a significant relationship between demographic characteristics (age, gender, occupation, marital status, education level and monthly incoming) and the attitudes toward private hospitals in home country (expenses, facility, technology, quality of care, doctor's ability and management efficiency).

H15 There is significant relationship between satisfaction after experiencing hospital services provided by the hospital (doctors' qualification, wide treatment variety, reputation, location, service, value for money, technology, facility, administration, trust, recommendation and communication) and the attitudes formed after experiencing hospital services provided by the hospital (still come if equivalent service available at home, likeliness to come back, recommend someone).
Not supported

Supported

Not supported

Not supported

Not supported

Not supported

Supported

Supported

Supported

Only four of the 15 hypotheses postulated were supported by the results, which rather indicate that preconceptions about the nature of medical tourism in this sample of respondents will need to be revisited. Of course, additional research might help to shine more light on these issues. 
Discussion: The majority of the respondents who came to Thailand to enjoy quality service were also here to check up on their health. Another group was here for other reasons which they did not want to disclose. It might also be important to note that people who came to the hospital for heart conditions and digestive conditions also said that they wanted to enjoy quality service. A similar number of people with digestive system related problems also claimed that they were here because they believed that what they needed was only available at this hospital. It would be naïve to think that patients from different countries can be satisfied by the same level of service or treatment facilities. How can a patient who came from the west have the same attitudes and level of satisfaction on the same health services with a patient who came from the east? Consequently, information such as which the patients were, how they thought, what was important to them and what their impressions were, would be very useful for any international or even to local hospitals. Even the private hospitals in Myanmar could use information such as the demographics or the attitudes or the decision factors of the patients who decided to seek treatment in a foreign hospital or prefer a hospital in another land, in order to improve their own shortcomings and update their knowledge and upgrade their own standards as well as equipment and facilities. This research can help figure out where they went wrong, where there weak points were and what were the advantages those foreign hospitals can provide that they cannot and, finally, might have a chance to stop the foreign currency leaking out of the country once and for all.

It was not just the private hospitals in the home country that can benefit from this research, the foreign hospitals could also draw up marketing plans to promote more influx of patients from home country now that they had and understood the demographics and the satisfaction factors. The attitude data would be useful to convince the patients that they had what their local competition lacked. Knowing the sources of information, the foreign hospitals can deliver their own marketing and public relation efforts to the target with appropriate income level directly with surgical precision. And on the other hand the private hospitals in home country can also do the same thing. For example, it was clear that people with a monthly income of 500,001-1,000,000 kyat/month got their information mostly from their friends and relatives. People did search for information on the internet; it cannot be entirely neglected because younger generation is becoming more familiarized with the internet so it seems that, even though it is not impressive for now, in a near future, the number of people searching for information on the net is likely to increase in the near future. In both figures, it was also apparent that many people got the information from their relatives. Having come from a culture of collectivism, the Burmese people usually trust and follow what their relatives, family and friends told them to. Therefore, it might be more productive for the foreign hospitals to concentrate their marketing efforts to impressing their Burmese patients and employing word-of-mouth or viral marketing campaigns, rather than concentrating on internet because information technology was not relied heavily nor trusted by the people who were just recently introduced to the technology.

A number of issues came up when the service provided by the hospital was discussed with the patients who participated in the questionnaire survey. Respondents were complaining about the insufficient number of translators available at the hospital to help the patients during the discussions with the doctors. Even though many of the patients understand English, they cannot fully understand if complex sentences and words were used, therefore translating service was essential and most important in serious cases. The ability of the translators was quite an acceptable level as most of the patients were quite satisfied with that particular service which helps both sides of the conversation but there were certain cases where the patients or the patients attendant were not satisfied with the way some of the translators' interpretation. This might be looked over as a minor inconvenience but in life threatening situations, such an occurrence of misinterpretation or misunderstanding can lead to tragic consequences. Consequently, it is believed that the translators should be constantly reassessed and trained.

Another complaint that came up during the time the research got a chance to talk with the patients before or after the questionnaire sessions, some of the patients complained about the miscalculations of medical bills, which they claimed were as high as tens of thousands of baht worth. In this age and time, and at a hospital this advanced, and this expensive, such kind of errors should never have occurred. At least 1-5\% of the respondents claimed they or their relatives and friends had this kind of unexpected and sad experience even though they assured that the hospital always handled the mistakes and refunded what was overcharged with a due apology and usually pointed out that there was some computer problem without transparent investigation into the mater. The hospital should set up a watchdog or monitoring 
system that double-check the double-billings, overcharging accidentally or other common and uncommon accounting as well as improving the record keeping practices. Further research to find out the same or more information on fields and variables than this research had explored but missed, on patients from more and different countries, coming to different hospitals in Thailand will be very beneficial for both the hospitals and the patients, in both home and host countries. The research findings presented in this research should be helpful to people not just from Myanmar but also for patients from different countries. The researcher wished and hoped that even with the culture and other barriers which made people different in their characteristics, attitudes and decision making process, there might be some particular information explored or described in this research that can be useful to a future fellow researcher.

\section{Conclusion}

Even though it was found that there was not much of a significant relationship between patients who visited other hospitals and who did not, it is believed that it is still advisable to search more information through as much possible medium as they can find and try different hospitals before making a decision to choose a hospital. It might be a difficult and taxing task, but since the health of the individuals should weigh more than the task to find out beforehand. The patients should also search more information about the doctors they were supposed to receive treatments from and more information on the length of stay a particular medical or surgical procedure requires. Requesting quotations on expected hospital charges for the approximate length of stay and planning for financial as well as documentary requirements before buying airfares and applying for a visa. Regarding the immigration requirements, both governments should have a special procedure for patients applying for medical or health related situations so that they can save lives while promoting a mutual beneficial relationship. However, both governments should also regulate and improve the quality and standard of their own health services systems to ensure unnecessary drainages which if left to accumulate can become a formidable sum because of the high prices associated with modern medical technologies. For the patients who found their appropriate choice of foreign hospital, they should calculate the length of stay, the distance to travel each both of which would affect the location they had to stay during undertaking treatment. The research site provides facilities for the patients and caretakers to stay during the patients' treatment; however, the availability was a problem at the rate of the patients the hospital has to handle. It would also be advisable for the patients to ask for the daily bills and charges so that they can check the number of doctor visits, the laboratory tests required, the medicine needed while their memory were fresh to prevent unnecessary miscalculation by the hospital. It would also be beneficial to find out cheaper but reliable sources for expensive drugs such as anticancer and certain immunology related medication and some vaccines.

\section{References}

Abdallat, M. M., El-Emam, H. E. S. (n.d). Consumer behavior models in tourism: Analysis study. Analysis Study, Department of Tourism and Hospitality, Faculty of Tourism and Archeology, King Saud University, Saudi Arabia.

Armario, E. M. (2008). Tourist satisfaction: An Analysis of its Antecedents. Catedrático de Marketing, 367382. Universidad, Sociedady Mercados Globales, Spain.

Baker, A., Daniels, C., Hylton, H. \& Montlake, S. (2006). Outsourcing your heart. Time (Asia Edition), 168 (5), 47-51.

Bangkok Bank. (2007). Health products and health services: Another industry in which Thailand is competitive (economic reports). Retrieved October 3, 2007, from http://www.bangkokbank.com/download/Health_Products_and_Health_Services.pdf

Belch, G. E. \& Belch, M. A. (2007). Advertising and Promotion: An Integrated Marketing Communication Perspective (7th Ed.). New York. McGraw Hill/Irwin.

Canadian Broadcasting Corporation. (2004). Medical Tourism: Need surgery, will travel. Retrieved October 3, 2007, from http://www.cbc.ca/news/background/ healthcare/ medicaltourism2.html.

Commonwealth Fund International Health Policy Survey. (2004). The commonwealth fund 2004, international health policy survey of primary care in five countries. Retrieved October 6, 2007, fromhttp://www.cmwf.org/usr_doc/ihp_2004_survey_charts.pdf

Crompton, J. L. (1979). Motivation for pleasure vacations. Annals of Tourism Research, 6, 408-424. 
Danell, S. C. \& Mugomba, C. (2006). Medical tourism and its Entrepreneurial Opportunities - A Conceptual framework for entry into the industry. Retrieved December 11, 2009, fromhttp://gupea.ub.gu.se/bitstream/2077/4671/1/2006_91.pdf

Dann, G. (1977). Anomie, Ego-Enhancement and Tourism. Annals of Tourism Research, 4 (2), 184-194.

Diethelm Travel. (2006). The Beauty of Travel. Retrieved October 2, 2007, from Diethelm: http://www.bangkokpost.net/tourismreview2006/24.html

Hoffman, K. D. \& Bateson, J. K. (2006). Services marketing: Concepts, strategies, \&cases (3rd ed.), Ohio, United States of America: Thomson South Western, 67-95.

Kanhasiri, C. (2005). Factors affecting the consumer's decision on buying shoes: A case study of students in Ho Chi Minh City, Vietnam, 8-9.

Kozak, M. \& Rimmington, M. (2000).Tourist satisfaction with Mallorca, Spain as an off-season holiday destination. Journal of Travel Research, 38 (1).

Mcgehee, N. G., Loker-Murphy, L. \& Uysal, M. (1996). The Australian international pleasure travel market: Motivations from a gendered perspective. The Journal of Tourism Studies, 7(1), 45-57.

Pachanee, C. \& Wibulpolprasert, S. (2006). Incoherent policies on universal coverage of health insurance and promotion of international trade in health services in Thailand. Retrieved October 5, 2007, from Health Policy and Planning: Oxford Journal: http://heapol.oxfordjournals.org/cgi/content/Abstract/21/4/310.

Thailand Board of Investment. (2007). Thailand: Asia's medical hub. Thailand Investment Review, 17(9), 13.

Tourism Authority of Thailand. (2003). Health tourism - The rising star. Retrieved October 7, 2007, from http://www.tatnews.org/emagazine/1983.asp

Tourism Authority of Thailand. (2007). Special Interest. Retrieved March 10, 2010, from http://www.tatnews.org/special_interest/health_medical_tourism/3423.asp.

Tourism Research and Marketing. (2006). Medical tourism: A global analysis. Retrieved October 6, 2007, fromhttp://www.traveldailynews.com/books_inside.asp?book_id=62.

Turner, L. (2007). First world health care at third world prices: Globalization, bioethics and medical tourism. Retrieved October 1, 2007, from http://journals.cambridge .org/action/displayAbstract;jsessionid=6C0BCD1D3E932F83C2D3E09FB9056721.tomcat1?from Page $=$ online\&aid=1316740.303-325.

United Nations World Tourism Organization. (2006). Mega-trends of tourism in Asia Pacific. Retrieved October 4, 2007, from http://www.unwto.org/regionaleast_asia _\&_pacific/publications/megatrend.pdf

Uysal, M. \& Jurowski, C. (1994). Testing the push and pull factors. Annals of Travel Research, 21(4), 844846.

Wesley, S., Lehew, M. \& Woodside, A. (2006). Consumer decision-making styles and mall shopping behavior: Building theory using exploratory data analysis and the comparative method. Journal of Business Research, 59, 535-548.

Wibulpolprasert, S. (2002). Thailand health profile. Retrieved December 3, 2007, fromhttp://www.hiso.or.th/hiso/picture/reportHealth/report/ThaihealthProfileE2004.pdf

Yoon, Y. \& Uysal, M. (2005). An examination of the effects of motivation and satisfaction on destination loyalty: a structural model. Tourism Management, 26, 45-56. 